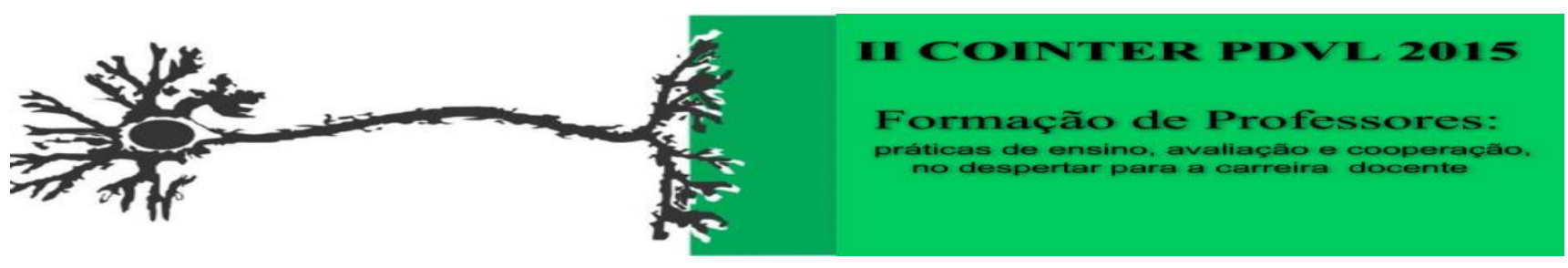

\title{
O ENSINO DE QUÍMICA CONTEXTUALIZADO COM A TEMÁTICA QUALIDADE DE ÁGUA
}

\author{
Apresentação: Comunicação Oral
}

Patrícia Brito Souza da Nóbrega ${ }^{1}$; Gesivaldo Jesus Alves de Figueirêdo ${ }^{2}$

\begin{abstract}
Resumo
O ensino e aprendizagem estão sempre em processo de reformulação para melhorar a compreensão dos saberes, indo de contra ponto ao ensino tradicional, no qual os conceitos e conteúdos são passados sem o uso da contextualização e experimentação. É fato que os Parâmetros Curriculares Nacionais (PCN) tratam a contextualização como uma ferramenta importante que amplia os conhecimentos de estudantes e professores sob a ótica da compreensão dos conceitos abordados em sala de aula. A Lei de Diretrizes e Bases da Educação (LDB - 9.394/1997) presume que o método da contextualização pode melhorar a compreensão dos conhecimentos, principalmente quando essa passa a evidenciar ações do cotidiano. Apesar da recomendação da lei, muitos professores e educadores não utilizam esta ferramenta e, acabam centrando a prática docente no método tradicional. De acordo com os Parâmetros Curriculares Nacionais para o Ensino Médio (PCNEM), a abordagem dos conteúdos da Química para o Ensino Médio é distante da realidade vivida por alunos e professores. Neste estudo, a contextualização da Química não é vista apenas para promover uma ligação artificial entre o conhecimento e o cotidiano, mas objetiva levantar a problematização, para o estudante, e que de forma participativa, cria-se as variáveis em busca das soluções. Neste sentido, o presente trabalho estabeleceu como premissa básica a compreensão de conteúdos da Química contextualizados com o processo de adsorção em coluna com fluxo contínuo. E os resultados obtidos evidenciam que a técnica de tratamento abordada entra no contexto da ampliação dos conceitos Químicos no tocante a interação iônica capaz de remover agentes contaminantes de águas e promovendo melhoria na qualidade de água.
\end{abstract}

Palavras-Chave: Ensino de química; contextualização e qualidade de água.

\section{Introdução}

Pesquisas no âmbito da educação, ensino e aprendizagem tem mostrado que os estudantes desenvolvem melhor a compreensão dos conteúdos quando os educadores deixam de empregar unicamente o conhecimento empírico e passam a utilizar também o conhecimento científico.

$1 \quad$ Licenciatura em Química/IFPB/PDVL/patriciadanobrega@ hotmail.com

2 Doutor/IFPB/PDVL/gesivaldojesus@ hotmail.com 
Projeta-se no meio científico, a utilização do processo de adsorção como alternativa para remover agentes contaminantes de águas e, esta técnica é bastante promissora, pois vem sendo amplamente estudada na remoção de íons dissolvidos em meio aquosa.

Com base nesta perspectiva, o presente estudo se apropriou do sistema de adsorção em batelada e em coluna com fluxo contínuo para ilustrar a remoção de agentes poluentes em águas e, consequentemente, foi feito uma contextualização dessa técnica de adsorção com os conteúdos da Química, tendo como público alvo os alunos do $1^{\circ}$ ano do Curso Técnico de Controle Ambiental Integrado ao Ensino Médio do Instituto Federal de Educação, Ciência e Tecnologia da Paraíba (IFPB), campus João Pessoa.

Sabe-se que no Brasil, os Parâmetros Curriculares Nacionais (PCN) configuram que o ato de contextualizar é uma ferramenta importante que pode atender tanto a docentes como discentes na compreensão de conteúdos ilustrados em materiais didáticos. Porém, os conteúdos são ministrados sobre uma perspectiva de tratamento periférico, satisfazendo apenas a eventuais curiosidades do estudante, com pouco esforço para o tratamento significativo de conceitos e uma abordagem voltada para o contexto real. A temática qualidade de água vem sendo explorado em sala de aula para aproximar as evidências do dia-a-dia do alunado com a prática da contextualização ilustrada a partir de experimentos alternativos voltados para tratamentos da água, apropriando-se do processo de adsorção em coluna com fluxo contínuo.

Nessa perspectiva, a técnica de adsorção vem sendo estudada como método alternativo de tratamento de águas e pode ser empregado como forma de contextualização destes conteúdos, principalmente quando são ministrados para turmas do Curso Técnico de Controle Ambiental Integrado ao Ensino Médio. Pois, compreende-se que para os alunos deste curso será importante ter essa oportunidade de entender como funciona a aplicação do processo de adsorção no tratamento de águas, a partir da abordagem correlativa entre a teoria e a prática.

Os conteúdos de Química (ligações químicas, reações químicas e separação de mistura) são abordados em sala de aula de forma teórica e sem aplicação prática e contextualizada. Todavia, podem ser trabalhados de forma diferenciada, ou seja, aplicando métodos práticos como a contextualização que leva a estudantada a despertar suas curiosidades e instigá-los a correlacionar a teoria com a vivência prática. Neste sentido, foi proposto contextualizar a técnica abordada com os conteúdos da Química visto em sala de aula, especificamente ligações químicas (interação iônica), reações químicas e separação de misturas. A abordagem destes conteúdos de forma contextualizada permite correlacionar a um ambiente de estudo teórico com a prática, tornando relevantes para os estudantes a aplicabilidade dos conceitos da Química. 


\section{Fundamentação Teórica}

De acordo com Paulo Freire (1987), as práticas curriculares de ensino em Ciências Naturais ainda são marcadas por uma relação de ensino caracterizada como "transmissão - recepção", sendo limitada à reprodução restrita do "saber de posse do professor", que "repassa" os conteúdos enciclopédicos ao aluno.

Já os PCNEM dispõem que as escolas mantenham a organização de conteúdos bem como possibilitem o diálogo entre a disciplina de Química com outras disciplinas, a fim de promoverem a construção de práticas pedagógicas que busquem a contextualização interdisciplinar dos conhecimentos.

A contextualização dos conteúdos de Química ministrados em sala de aula denota ensinar para o aluno aspectos importantes do seu cotidiano, de modo a torná-lo capaz de tomar decisões, participar de contextos da Química considerados atuais e interdisciplinares (COSTA, 2010).

Segundo FONSECA (2011), a mudança nas metodologias tradicionais com a inclusão das aulas experimentais estimula o desenvolvimento conceitual, pois oportuniza os estudantes na elaboração de novas ideias e ao mesmo tempo contribui na ampliação de seus conceitos.

Partindo desse princípio, o processo de adsorção que é um fenômeno físico-químico e tem suas múltiplas aplicações, podem ser utilizado na contextualização de conteúdos como ligações químicas e separação de misturas.

A adsorção pode ocorrer por dois tipos: a física e a química; o que as define são as forças de ligação entre as moléculas que estão sendo adsorvidas e o adsorvente. Na adsorção física (ou fisiossorção), as moléculas se ligam ao adsorvente utilizando forças relativamente fracas e sua natureza química permanece sem alteração. Essas forças são idênticas às forças de Van der Walls, que tornam as moléculas fisicamente presas ao adsorvente. Na adsorção química (ou quimiossorção), há uma interação química através de ligações das valências livres das moléculas do adsorvente e do adsorvato. A ligação química formada é, em geral, muito forte, o que torna o processo praticamente irreversível (MASEL, 1996).

Os adsorventes são materiais, naturais ou sintéticos, cujo acesso às superfícies internas dos seus poros passa a depender de uma seleção natural que ocorrerá entre o adsorvente e o adsorvato. Do ponto de vista econômico, um adsorvente deve possuir determinadas características, em destaque: área de superfície elevada, seletividade, eficiência, resistência mecânica, menor perda de carga possível, inércia química e baixo custo (EREN, 2008). 
No âmbito comparativo a adsorção se distingue da absorção em que; a absorção implica no acúmulo da substância absorvida em todo o volume do absorvente enquanto na adsorção o fenômeno ocorre na superfície do adsorvente.

Os estudos cinéticos de adsorção relacionam os fatores determinantes no processo de adsorção. Nesses estudos são envolvidos os vetores decisivos para identificar a eficiência do processo de adsorção do poluente pelo tempo de contato com o adsorvente.

Os modelos cinéticos são importantes na determinação do tempo necessário para se obter o equilíbrio do processo de adsorção e na apreciação das velocidades de adsorção (VADIVELAN e KUMAR, 2005).

As velocidades de adsorção são encontradas a partir da variação da concentração do adsorvato com o adsorvente em função do tempo de contato (VARSHINEY; KHAN; GUPTA e MAHESHWARI, 1996). A determinação da velocidade de adsorção é significativa para o entendimento do processo de remoção de poluentes em meio aquoso.

O processo de adsorção é considerado em equilíbrio quando não se detecta mais variação na concentração da espécie adsorvida durante o período de contato entre adsorvente e o adsorvato.

\section{Metodologia}

A metodologia utilizada para o desenvolvimento doa pesquisa foi pautada no estudo qualitativo, quantitativo, investigativo, correlativo e significativo (LAKATOS e MARCONI, 2009). Para tanto, foi feito o plano de trabalho em função dos objetivos propostos, considerando a prática pedagógica de cunho técnico e didático.

A princípio foram levantados dados do quantitativo de alunos contemplados na pesquisa. Em seguida, ocorreu o desenvolvimento das atividades proposta no plano de trabalho, tendo como público alvo alunos do $1^{\circ}$ ano do Curso Técnico de Controle Ambiental Integrado ao Ensino Médio (do campus João Pessoa), visto que os conteúdos da Química que podem ser correlacionados com a técnica da adsorção são abordados nesse ano. Notadamente, este público foi o escolhido por considerar relevante o conhecimento cientifico da utilização da técnica de adsorção no tratamento de águas.

Portanto, a pesquisa apropriou-se dos processos de adsorção para remover ou reduzir agentes contaminantes de águas e, assim, evidenciou a correlação da prática experimental com a interação dos conteúdos de ligações químicas e separação de misturas. Com a participação dos alunos do $1^{\circ}$ ano do curso técnico de controle ambiental, foi montado o procedimento experimental 
na escala de laboratório (Figura 1), que contou com a técnica de adsorção em coluna com fluxo contínuo, utilizando como adsorvente a casca do marisco (mexilhão - Anomalocardia brasiliana). Material este que se apresenta eficiente na adsorção de íons como alumínio $\left(\mathrm{Al}^{+3}\right)$ nitrato $\left(\mathrm{NO}_{3}{ }^{-}\right)$, cloretos $\left(\mathrm{Cl}^{-}\right)$e outros (FIGUEIREDO, 2013).

Figura 1 - Contextualizando os conceitos da química com o processo de filtração em coluna.|
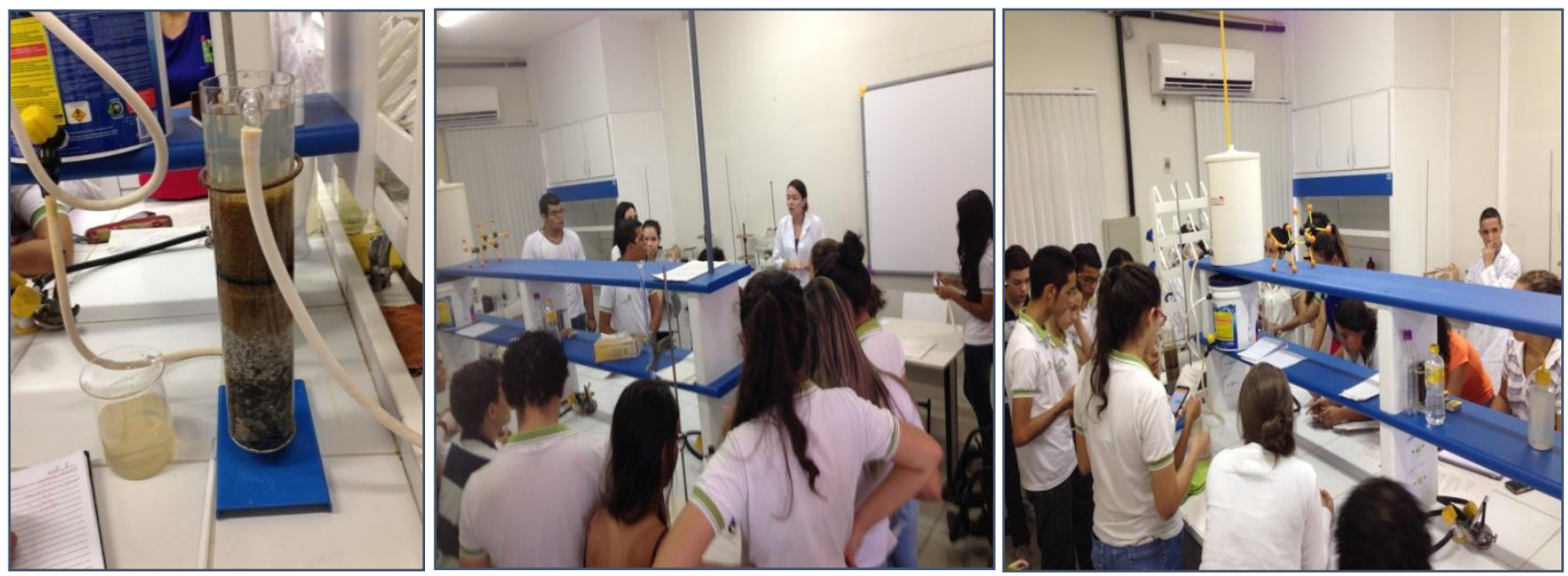

Fonte: Própria pesquisa

A aplicação do sistema de adsorção em batelada envolve um volume fixo de amostra de água e uma massa definida do material adsorvente. No procedimento experimental teve um volume de $50 \mathrm{~mL}$ de água (amostra há ser tratada) que foi adicionado a uma massa de 0,1000 g do material adsorvente (casca de marisco) em um erlenmeyer, mantido em banho-maria sob agitação contínua (150 rpm) e controle de temperatura, nos diferentes tempo de contato: 5, 10, 20 e 30 minutos; depois, ocorreu a separação por filtração utilizando papel de filtro tarja azul. Em seguida, efetuou-se a análise da amostra para verificar o quantitativo adsorvido dos parâmetros investigados e, para uma efetiva correlação, analisou a amostra de água antes da adsorção.

O sistema em coluna foi composto por um tubo de vidro transparente com a seguinte dimensão: $30 \mathrm{~cm}$ de altura na extremidade e $10 \mathrm{~cm}$ de diâmetro, fechado em baixo (com entrada de água bruta por baixo, na lateral) e aberto em cima (com saída de água tratada na parte superior, pela lateral). Neste sistema a água entra por baixo no tubo (coluna) com uma vazão definida, sobe passando pelo material não adsorvente (camadas de brita, cascalho fino e areia) e adsorvente (camada de casca de marisco) até chegar à parte superior e, antes de transbordar, sai pela lateral da coluna. Foram coletadas amostras de água na saída da coluna, num intervalo de tempo pré- 
estabelecido (5, 10, 20 e 30 minutos) e foi correlacionado o quantitativo adsorvido pelo tempo de contato com o material adsorvente.

A correlação dos resultados obtidos nos processos de adsorção indicou a proporção do quantitativo de íons removidos e, foram contextualizadas: as interações iônicas ocorridas; de que forma aconteceram; com quais intensidades, que tipo de reação, onde e como ocorreu a separação de mistura.

Para avaliar o método da contextualização aplicada, foram elaborados questionários que contemplaram perguntas de cunho técnico e pedagógico. E o nível de compreensão dos alunos foi analisado a partir da aplicação do pré e pós-questionários.

\section{Resultados e Discussão}

A partir das informações adquiridas com o resultado da aplicação dos questionários pré e pós-avaliativo, constata-se que os alunos participantes da pesquisa ampliaram seus conhecimentos no tocante aos conteúdos químicos abordados. O nível de entendimento dos alunos antes e depois da contextualização pode ser correlacionado e, avalia-se que a prática metodológica aplicada oportunizou uma realidade vivenciada por esse público quando acompanhou a ilustração da técnica de adsorção.

Constatando que a metodologia foi bem sucedida, ocorrendo com uma aprendizagem significativa para os discentes. Pois, verifica-se que os mesmos identificam e compreendem que a adsorção ocorre fisicamente, quando há interação entre as substâncias por meio da força de Van der Walls e que a mesma é fraca e esta adsorção pode ser reversível.

Portanto, percebe-se que os alunos assimilaram os conceitos abordados a partir da contextualização, também, mostraram-se interessados e participativos, o que contribuiu para melhor compreensão da problemática "qualidade da água", assunto que permeia a curiosidade do estudante e que faz parte de uma vivência prática do cotidiano.

\section{Conclusões}

Neste trabalho a abordagem dos conteúdos Químicos ocorreu de forma atrativa e contextualizada com o cotidiano dos alunos participantes da pesquisa. E diante da análise dos questionamentos, posicionamentos e colocações, se observou que os alunos desenvolveram 
competências no âmbito qualitativo e quantitativo, bem como obtiveram informações necessárias para o desenvolvimento do ensino e aprendizagem.

Notando que a metodologia contribuiu para que o público alvo compreendesse melhor as temáticas, tendo em vista a ligação com os conteúdos químicos, acarretando, assim, em um melhor embasamento no questionário final, pois identificam e interpretam o senso comum que apresentaram inicialmente.

Tal método foi bastante aprovado pelos educandos, sendo, portanto, requisitado que mais aulas pudessem proporcionar a mesma abordagem. Na qual os mesmos veem aplicação direta dos conteúdos no futuro profissional.

Desta forma, sendo ativos na construção de valores necessários para a compreensão do que os cercam, podendo tomar decisões e atuar para solucionar, bem como divulgar tais conhecimentos.

\section{Referências}

EREN, E. Removal of cooper ions by modified Unye clay, Turkey, Journal of Hazardous Materials, v. 159, n. 235, 2008.

FIGUEIRÊDO, G. J. A. Tecnologia Sustentável para Tratamento de Efluentes de Estações de Tratamento de Água com Aproveitamento na Agricultura Irrigada. Campina Grande-PB. 2013. Tese de Doutorado. Centro de Tecnologia e Recursos Naturais, UFCG.

MARCONI, M. A.; LAKATOS, E. M. Metodologia do Trabalho Científica. $7^{a}$ ed. São Paulo: Editora Atlas, 2009.

MASEL, R. Principles of Adsorption and Reaction on solid Surfaces. Wiley Series in Chemical Engineering. $1^{\text {a }}$ ed. 1996.

BRASIL. Ministério da Educação - Secretaria de Educação Média e Tecnológica. Parâmetros Curriculares Nacionais para o Ensino Médio. Brasília: MEC/SEMTEC, 1999.

FONSECA, M.R.M. Completamente Química: Química Geral, São Paulo, 2001.

COSTA, L. C.; MARCIANO, E. P.; CARNEIRO, G. M. B.; SOUSA, R. M. DE; NUNES, S. M. A Química Forense como unidade temática para o desenvolvimento de uma abordagem de Ensino CTS em Química Orgânica. XV Encontro Nacional de Ensino de Química (XV ENEQ) - Brasília, DF, Brasil - 21 a 24 de julho de 2010.

FREIRE, P. Pedagogia do oprimido. Rio de Janeiro: Paz e Terra, 1987.

BRASIL. Lei de Diretrizes e Bases da Educação Nacional, Lei no. 9.394, de 20 de dezembro de 1996. 
VADIVELAN, V.; KUMAR, K. V. Equilibrium, kinetics, mechanism and process design for the sorption of methylene blue onto Rice husk. J. Colloid Interface Sci., v. 286, p. 90 - 100, 2005.

VARSHINEY, K. G.; KHAN, A. A.; GUPTA, U.; MAHESHWARI, S. M. Kinetics of adsorption of phosphamidon on antimony $(V)$ phosphate cátion exchanger: evaluation of the order of reacttion and some physical parameters. Collids and Surfaces: A physicochem Engin. Aspects, v. 133, 1996. 